\title{
As lutas dos indignados espanhóis em 25 de setembro de 2012 em Madrid
}

\author{
Diego de Carvalho \\ UNISINOS \\ E-mail: diegodcarv@uol.com.br
}

\begin{abstract}
Resumo
Neste artigo buscamos analisar um dos acontecimentos mais importantes das lutas espanholas, o 25 de setembro de 2012. Buscamos mostrar que os coletivos envolvidos produziram um acontecimento auto-organizado, sendo o caos criado pela repressão policial. Mais importante no artigo é a possibilidade de am-

pliar os componentes de luta na Espanha, neste caso a população espanhola, que de forma corrente é considerada passiva por não sair as ruas nas manifestações. A aproximação mais importante do empírico se refere a produções minoritárias na web como também a produções dos meios de massa.
\end{abstract}

Palavras-chave: Multidão; indignados espanhóis; Web 2.0; Foucault.

\section{The struggles of the Spanish indignados on September 25, 2012 in Madrid}

\begin{abstract}
In this article we analyze one of the most important events of the Spanish struggle, the September 25, 2012. We seek to show that collectives involved produced a selforganized manifestation, being the chaos created by police repression. More important in this article is the possibility of

expanding the components of fighting in Spain, in this case the Spanish population that is considered passive in part by not going to the streets in demonstrations. The empirical approach refers to web minority productions as well as productions of mass media.
\end{abstract}

Keywords: Crowd; spanish struggles; Web 2.0; Foucault. 


\section{Introdução}

TO início de 2011 vimos revoltas no norte do continente africano, tendo como ponto inicial a Tunísia. As lutas, em pouco tempo, se espalharam pela Argélia, Síria, Líbia, pelo Líbano, Egito, Iraque entre outros países. As revoltas, denominadas de Primavera Árabe e de Revolução Democrática Árabe, foram consideradas "la primera gran oleada de protestas laicas y democráticas del mundo árabe en el siglo XXI.” (http://es.wikipedia.org). As redes sociais foram determinantes na organização e difusão das lutas, tanto internamente, quanto na divulgação para o resto do globo - claro que também a mídia de massa teve seu papel na disseminação de informação sobre o que acontecia no mundo árabe.

Em maio de 2011, influenciados por essas revoltas e pela crise que afeta muitos países europeus jovens tomam a principal praça de Madrid, na Espanha. De início, programaram manifestações, no entanto, após assembleia decidiram acampar. A partir daí criaram um ciclo de lutas que tomou as principais praças de mais de 80 localidades na Espanha. Os sujeitos atores dessas manifestações foram chamados de "indignados" e reunidos sob a denominação de Movimento 15 de Maio - 15M. No artigo, também chamamos os sujeitos envolvidos nas lutas de "indignados", mas não fazemos referências mais diretas ao $15 \mathrm{M}$, já que este nos anos seguintes a 2011 é apenas mais um dos nós nas lutas espanholas. Aliás, nó que é o mais importante em nossa pesquisa de doutorado.

As lutas se espalharam por toda Europa após a revolta espanhola principalmente, entre os países mais afetados pela crise, como Portugal e Grécia. Em outubro de 2011 acontece a difusão global de lutas ocorrendo manifestações em todos os continentes, e também no Brasil. No país são formadas ocupações de praças em São Paulo, Rio de Janeiro, Salvador e Porto Alegre entre outras cidades. Isso dura até o início de 2012. Em 2013, acontecem revoltas em massa na Turquia, novamente no Egito, obviamente, na Europa e também em todo o Brasil; ou seja, o devir revolucionário que começou no mundo árabe e se espalhou no ocidente a partir da Espanha, continuou movimentando boa parte do globo.

Neste artigo centramos nossa análise em um dos acontecimentos mais importantes das lutas espanholas, as demonstrações em Madrid que começaram em 25 de setembro de 2012, o 25S. Decidimos investigar esse acontecimento, 
pois em nossa pesquisa de doutorado um dos objetivos é fazer um mapeamento das inúmeras manifestações ocorridas na Espanha desde o 15 de maio de 2011, e também, pois as lutas do $25 \mathrm{~S}$ apresentaram elementos singulares no caso espanhol.

O que nos interessa no $25 \mathrm{~S}$ é a composição heterogênea, aberta, em constante movimento dos coletivos envolvidos; o que impede o endurecimento identitário facilmente identificável. Mas mais importante neste texto é o fato de que o acontecimento revela uma outra singularidade de indignação espanhola: a população. No $25 \mathrm{~S}$ um senhor enfrentou sozinho a polícia para defender manifestantes, fato que será apresentado de forma sistematizada no texto. Pensamos que isso teria sido feito por qualquer pessoa da população. Assim, percebemos que há uma indignação que extrapola os sujeitos e coletivos que participam de forma mais consistente nas manifestações e nas atividades constantes produzidas pelos nós das lutas espanholas. Podemos chamar, portanto, os indignados de multidão, como esta é conceituada por Antonio Negri (2005; 2006): todos os que vivem sob o domínio do poder, que têm suas vidas exploradas, e mais, os sujeitos de resistência que desejam outra realidade.

O conceito de Multidão de Negri e o conceito de Devir de Deleuze são centrais em nossa pesquisa intitulada Devires Minoritários do Movimento 15 de Maio. Neste artigo deixamos um pouco de lado o eixo teórico e partimos para uma análise mais empírica. No entanto, os conceitos estão sempre presentes de uma forma ou de outra. Neste texto temos como conceito principal o de "entusiasmo para com a revolução" de Kant, ou melhor, como este foi apropriado por Foucault.

Quanto à aproximação do empírico ela é dividida no artigo em duas vias: primeiro, off line, se refere a contatos que tivemos com os indignados em viagem feita para Espanha em 2011. Mesmo que o acontecimento seja do ano posterior, nossa experiência of line na Espanha nos ajuda a pensar o desejo de revolução da população. Na Espanha, participamos de eventos diferenciados, como assembleias, encontros de coletivos, além de termos feito entrevistas com sujeitos atuantes nas lutas. A segunda via, mais importante até o momento para a pesquisa, se refere às produções na web feitas pelos indignados, que usam exaustivamente as redes para difundir informações, e nós as usamos como forma de reconstruir os acontecimentos. Também as produções das mídias de massa nos ajudam, pois as estamos percebendo como representantes dos indignados, mesmo que seja de forma parcial. 


\section{O 25S - Primeira parte}

O 25S, que iniciou em 25 de setembro de 2012 e se desenrolou até o dia 29, apresentou uma imprevisibilidade caótica, tanto na reunião de inúmeros grupos sem uma identidade afirmada, quanto na transformação da composição destes grupos. Importante detalhar que toda essa imprevisibilidade não impediu que a manifestação acontecesse de forma auto-organizada, sendo o caos produzido pela máquina bem estruturada, burocrática do poder político e seus "cães de guarda", a polícia. Como declara o informativo alternativo Kaos Em La Red:

Madrid ha sido un campo de batalla. Policías con armas largas en lo alto de las azoteas en torno al Congreso de Diputados. Detenciones arbitrarias e identificaciones a ciudadanos que deambulan por las calles sin razón alguna. Porras, patadas, alones de pelos y cuanta cosa sirva para golpear a los indignados de este gran país, de esta gran ciudad. Ataques y detenciones selectivas para fragmentar la ira y el dolor de un pueblo que clama por un cambio de ruta y de principios. "Antidisturbios" que pisotean cuerpos, cabeza o brazos, para anular y amedrentar a los que exigen una ruta diferente. La dignidad está efervescente en las calles. [...] Madrid se crece ante la fuerza bruta. (www.kaosenlared.net)

O 25S reuniu pessoas indignadas com o poder, que estiveram presentes para expressar isso, a partir de palavras de ordem, cartazes, registros midiáticos, cantos e panelaços. Obviamente, como não estavam lá para uma partida de críquete, nem para um show de música pop, como estavam lá para demonstrar indignação, seus coros, palavras de ordem, dizeres não eram "recadinhos amorosos" para o governo, mas expressões do desejo do fim, da morte do sistema.

Tudo ocorreu razoavelmente, sem sinais de violência da parte dos indignados; a violência foi gerada, como dissemos, pela polícia, exatamente aqueles que são contratados para manter a paz, a tranquilidade dos cidadãos. Mas não no $25 \mathrm{~S}$ como em muitos outros acontecimentos: a polícia gerou o caos entre a multidão, a atacou sem piedade, para defender o poder.

Nos últimos anos é comum a postagem de imagens e textos expondo as táticas da polícia de literalmente, gerar caos em manifestações: reúnem policiais jovens de ambos os sexos; esses se vestem como os jovens indignados, 
muitas vezes de negro, com capuzes ou lenços para esconder o rosto. Então, começam a praticar ações de violência.

Um caso ganhou certa repercussão nas redes sociais e pode ser contemplado em vídeo postado no youtube (www.youtube.com). Nele policiais fardados e policiais a paisana, na demonstração do dia 26 de setembro, detêm um homem de preto, o derrubam no chão, e ele grita: "sou companheiro, sou companheiro". Os policiais dizem: "este é companheiro"; ou seja, era mais um policial infiltrado que estava causando confusão na demonstração e que não havia sido reconhecido.

Outras imagens em vídeo mostram algo parecido, agora no dia 25 de setembro (www.youtube.com). Nas legendas do vídeo, diz-se que sujeitos que começaram um tumulto na demonstração eram policiais infiltrados: um grupo de encapuzados, que usavam símbolos da esquerda como bandeiras vermelhas e negras.

Nas lutas que aconteceram nos dias 25, 26 e 29 de setembro em Madrid, milhares de manifestantes se reuniram em frente ao congresso. A intenção dos manifestantes não era totalmente clara, sendo modificada ao longo das preparações, mas inicialmente, a ideia era impor ao congresso "[...] a la elaboracion de una nueva Constitucion (tomando en parte como inspiracion el modelo historico de las revoluciones liberales), que iria precedida de una "destitucion" del gobierno actual." (Comisión de Análisis Sol 15M, p. 3). Um dos teóricos dos indignados, Victor Sanpedro, em artigo, expressa outras demandas dos nós que compuseram o $25 \mathrm{~S}$ :

[...] se pide más democracia. Se impugna el desmantelamiento del muy precario Estado de Bienestar y la precarización de la fuerza de trabajo que comparten ambos partidos. Y se critican los giros pendulares que impiden la continuidad de políticas centrales para una sociedad (sanidad, educación, organización del estado...). (Sanpedro, 2012)

Também outro meio de comunicação publica um longo artigo com muitas informações extraídas das redes sociais dos coletivos que compuseram a preparatória, apresentando o seu ideário:

[movimento] "de carácter social, antineoliberal, anticapitalista y democrático", [luta] por la soberanía, una democracia directa y parcipativa, donde las necesidades básicas de las personas estén cubiertas y donde 
caben valores como: el reparto de la riqueza equitativo, el rechazo rotundo a la Guerra, la convivencia con el medio ambiente, la denuncia de la explotación, la justicia y reparación histórica, la no mercantilización de la totalidad de los recursos, el apoyo a la emancipación y soberanía de los pueblos, la defensa a las personas migrantes y la oposición a políticas de alianzas con el liberalismo capitalista, recogiendo las diversas corrientes ideológicas antes citadas. (http://iniciativadebate.org

Aqui importante frisar que a imposição de mudanças macro, de certas demandas frente ao governo, que nunca são atendidas, mesmo mediante manifestações em massa, isso não se sobrepõe ao processo revolucionário expresso na tomada das ruas. Assim, o bloco de manifestações que ocorrem periodicamente, cria um território rico em si mesmo, produzido a partir da indignação da população. Dizemos isso, pois nosso objetivo na pesquisa é mapear o devir revolucionário dos indignados, seus processos, sua riqueza atual, o que está acontecendo e não tentamos pensar no que vai acontecer, o futuro da revolução, se o governo vai atender as exigências dos coletivos.

As fontes oficiais dizem que nos momentos mais expressivos havia seis mil pessoas; outras fontes de mídias corporativas falavam em algo entre 50 e 100 mil pessoas. Fontes do movimento calcularam entre 20 e 60 mil pessoas. Vimos muitas fotos e imagens panorâmicas em vídeo. A Praça Neptuno, próxima ao congresso, estava repleta de uma massa densa.

Em informe publicado na página de um dos nós mais importantes das lutas na Espanha, a Acampada Sol, é exposta a preparação para o acontecimento e declarada a indeterminação da organização da convocatória. O primeiro grupo a dar o empurrão inicial foi a Plataforma em Pie, que segundo o documento era formada por inúmeros coletivos: "Un grupo de activistas que trabajamos en distintos colectivos (15M-Dry, DDHH, PAH, III Republica, Constituyentes,...) nos hemos reunido en un frente comun para llevar a cabo esta accion, 25S 'Ocupa el congreso'.' (Comisión de Análisis Sol 15M, p. 1). Também é dito que essa informação não era precisa "Mas tarde, esta informacion se borro. Tambien se sugirio en varias ocasiones que se trataba de gente relacionada con Anonymous, aunque la informacion que circulaba era contradictoria." (Comisión de Análisis Sol 15M, p. 1).

Em documento da própria Plataforma em Pie, o coletivo se apresenta de forma mais explícita dizendo quem está envolvido na sua composição: 


\begin{abstract}
Somos personas reunidas en un movimiento de carácter social, antineoliberal, anticapitalista, antipatriarcal y democrático. [...] En esta plataforma confluyen diferentes sensibilidades representadas en diversas corrientes de opinión y movimientos sociales, entre las que se incluyen: Corrientes republicanas de izquierda, Corrientes de izquierda social, Corrientes libertarias, movimiento $15 \mathrm{M}$, movimiento antiglobalización, corriente antipatriarcal, movimiento obrero, movimientos ecologistas... (http://plataformaenpie.wordpress.com)
\end{abstract}

Estes "inician la difusión de la misma desde el anonimato y por Facebook inicialmente. Mas tarde crean el blog de la Plataforma y una cuenta en twitter, pero evitan en todo momento decir quiénes son (en parte por miedo a la represion)." (Comisión de Análisis Sol 15M, p. 1). O documento também dá importância para um segundo momento da preparação e convocatória do acontecimento, a criação da Coordinadora 25S, esta mais aberta, que traz novos objetivos para a demonstração programada.

Cabe destacar que a Coordinadora $25 \mathrm{~S}$ se mantém bem ativa nos meses posteriores, e ainda há atualizações em seus canais de informação. Nos cadastramos na página da Coordinadora (http://coordinadora25s.wordpress.com) e recebemos via e-mail informações. Desde setembro de 2012, as atualizações são frequentes, às vezes, acontecendo hiatos nas postagens. Quanto a Plataforma en Pie, ela foi posteriormente, dissolvida; ou seja, durou um pouco mais de um semestre.

Creemos que llegado un momento determinado todo movimiento debe evolucionar o ser superado y que en nuestro caso ha llegado el momento de parar y de replantearnos la dirección a seguir. Aunque la plataforma cese indefinidamente su actividad, la lucha debe seguir, y animamos a que así sea y que se pongan en marcha iniciativas de resistencia que puedan sorprender y desafiar al régimen.

(https://plataformaenpie.wordpress.com)

Interessante que no mesmo comunicado declara-se que a dissolução do coletivo pode ser efêmera, o que confirma ainda mais toda a indeterminação que envolve a organização da plataforma e assim da composição das lutas na Espanha:

La Plataforma se reactivará de nuevo si se da alguno de los siguientes casos: a) Que tengamos una nueva propuesta que aportar, que pueda 
ilusionar y despertar a la sociedad, acercándonos al cambio deseado. b) Que el rumbo de los acontecimientos se precipite y la sociedad se muestre verdaderamente dispuesta a presentar batalla. En este caso pondremos todos los medios a nuestro alcance para apoyar y empujar la ruptura y el cambio. (https://plataformaenpie.wordpress.com)

Muitos meios fizeram a cobertura do $25 \mathrm{~S}$ a partir de notícias minuto a minuto. Abaixo expomos o que foi dito no site La Haine (www.lahaine.org), que traz notícias de movimentos de resistências contemporâneos. Já no início das postagens diz que muitos ônibus estavam vindo de outras localidades pra acudir a manifestação. "Cabe destacar que varios autobuses que llegaban a Madrid desde distintos puntos del Estado han sido bloqueados a la entrada de la ciudad.". As 15:00h, segundo o La Haine, próximo do local das manifestações posteriores havia uma concentração com comidas populares: "La convocatoria se desarrolla ahora en el Paseo del Prado, donde tiene lugar una comida popular. Hasta aquí ha venido la gente desde Atocha y desde Plaza de España, los dos puntos donde recibieron a los manifestantes llegados de otras ciudades.". Também outras cidades estavam fazendo demonstrações como em Sevilha, com "unas 3000 personas, convocadas por el SAT, rodean el Parlamento andaluz. Los participantes avisan: "O nos dejan entrar o entramos a las bravas"." Já no local das manifestações em Madrid, por volta das 19:30 "los antidisturbios, con casco y escudo, han empezado a cargar contra la gente que se agolpaba junto a las vallas.” Das 21:00h até a 1 h do outro dia toda a narrativa é referente a cargas policiais. Retornaremos a esse dia e horário final na última parte do texto, na qual tratamos do caso do Bom Homem do 25S.

\section{O 25S - Segunda parte}

Continuando a narrativa, agora centramos no último dia do acontecimento que começou em 25 de setembro. É declarado na página do El Pais: "La protesta del 25-S vuelve a la plaza de Neptuno. Tras la manifestación que se saldó con 35 detenidos y más de 60 heridos, los convocantes han vuelto a llamar a los ciudadanos a protestar". (http://politica.elpais.com)

La Coordinadora 25-S ha convocado una nueva protesta a partir de las seis de la tarde en Neptuno (Plaza de Cánovas del Castillo) y la Puerta del Sol con el objetivo de volver a rodear el Congreso por tercera vez 
esta semana y pedir la dimisión del Gobierno y el inicio de un proceso constituyente. Esta tercera protesta se produce a pesar de que la juez de Instrucción número 8 de Madrid haya considerado que "existen motivos bastantes"para estimar que los detenidos durante la primera protesta del pasado 25 de septiembre cometieron un delito contra las Instituciones del Estado. El próximo lunes decidirá si se inhibe a favor de la Audiencia Nacional. (http://politica.elpais.com)

Imagens no streaming do El Pais, agora já na mobilização, servem como nosso ponto de partida na construção da narrativa: imagens panorâmicas dão uma visão ampla da multidão, toda a praça repleta de gente, cantando, apitando, fazendo batucada. Cantam "televisão, manipulação". Cornetas tocam. Há um murmúrio alto de pessoas conversando. Muitos cartazes escritos: "Não". O Não que marca as palavras de ordem do movimento: "Não nos representam", "Não hay pan para tanto chorizo". Frases estas que também percorrem as redes sociais. Um furgão com pessoas em cima, bem no centro da manifestação. Melhor estar na manifestação, vivê-la sem distanciamento, e depois de vivê-la pegar os dados na web. Porém, na impossibilidade de estar em uma demonstração, estar na web possibilita uma narrativa de outra natureza.

Parece uma festa, só que perigosa; estão todos de frente para uma massa policial, bem armada. Sabem que pouco podem fazer frente à repressão, pois o poder da polícia tenta ser absoluto e mais, acima da própria lei. Os jovens gritam "demissão, demissão" Alguém fala em um alto falante ou megafone, puxa palavras de ordem. Parece que a polícia está mais organizada que nos dias anteriores, a grade que separa manifestantes e os representantes do governo está mais fortificada.

Muitos assobios, cantos. Parece de cima um show, todos de frente ao congresso, onde está a polícia e a grade. Três jovens sobem nos ombros de outros, ficam de pé, o que gera alguns gritos de ovação; os jovens se abraçam para não perder equilíbrio, mas também como gesto fraterno. Os garotos abrem uma bandeira espanhola. Aliás, há várias bandeiras da Espanha sendo empunhadas.

Estávamos com o tablet ligado no streaming do El Pais. Com o notebook, estávamos conectados no twitter que apresentava comentários sobre o que es- 
tava passando; no facebook, apareciam alguns comentários e links, como também fotos que eram postadas em perfis.

Outros cartazes nas imagens ao vivo: "repressão, censura, tortura." "Não somos maquinas, não somos gado, somos homens" Um cartaz com o símbolo da paz virado. Outros cartazes: "divida odiosa, referendo já", "banqueiro bom é banqueiro morto", "ao governo lhe agrada quando tu te calas", "pensa, se organiza e luta", "menos Franco e mais pão branco". Outros cartazes com números dos desempregados na Espanha, comparando com outros países da Europa. "Democracia é diferente de ditadura de quatro anos". Em certos momentos, gritos em massa, um som parecido com um mantra. Uma figura vestida de negro, alta, um circence, talvez representando a morte dos governantes, ou do povo pelas medidas.

No fim da demonstração, começamos a receber informações de que haveria uma assembleia para fechar a manifestação. "Atencion: ha empezado la asamblea en Neptuno. Las personas q estais delante frente al congreso acercaros al lateral d cibeles." (@ democraciareal). A primeira coisa que é feita na assembleia é a leitura de um manifesto.

A assembleia, nós contemplamos via streaming no site Bambuser (http://bambuser.com). A mídia apresentava boas imagens, sem cortes, o que nos permitiu uma visão geral, com alguns detalhes. Relatamos o que foi dito sem nomear os sujeitos, pois isso não foi feito, apenas abria-se espaço para quem desejasse falar. Na sequencia cada sujeito será referenciado por números. Antes de começar as falas já programam uma outra assembleia para o dia seguinte. 1. Sugere trabalhar localmente. 2. Incita medidas efetivas, luta real, não virtual, luta pacífica. Todos aplaudem. 3. Importante pensar nas pessoas que não vivem em Madrid e não podem acudir as demonstrações. Todos aplaudem. 4. Fala da importância dos meios e em não reforçar os meios corporativos. Todos aplaudem. 5. Abrir processo constituinte para unificar as lutas sociais em um processo participativo, que se difunda para os bairros e assembleias populares. Fazer a constituição com as próprias mãos. Aplausos. 6. Declama uma poesia sobre o gênero humano e a beleza do comum da vida. Fala sobre amor, o governo do amor. Todos aplaudem. 7. Um mediador fala, todos aplaudem e sorriem.

Percebemos uma leveza nas palavras, nos sorrisos, nas vozes, todos unidos, muito diferente da seriedade da macropolítica. Sente-se um certo descompromisso que diz respeito à juventude, um amor pela vida, longe do can- 
saço imposto pelo poder. E todos passaram o dia todo em luta na demonstração, de pé, cantando, agindo, com os nervos a flor da pele, pois a polícia estava lá, sempre pronta para acabar com a alegria; e todos estavam ali na assembleia, entre risos, aplausos, mostrando boa vontade, amando os seus. Longe de todo estresse, a possibilidade do desemprego, a pobreza muito próxima, o fim dos sonhos, mesmo assim todos cultivando a alegria. Uma forma jovem de encarar a vida.

No Twitter umas últimas palavras sobre a assembleia e decisões do que fazer daqui pra frente: "Ha terminado la asamblea. Gracias a todas las personas q habeis venido a luchae $\mathrm{x}$ una democracia real. Nos vemos mañana $\mathrm{n}$ el retiro 11h.” (@ democraciareal). "El \#30s habrá otra asamblea en el retiro. Se debatirán decisiones sobre la continuidad...” (@Voces25S ).

\section{O bom homem do $25 \mathrm{~S}$}

No $25 \mathrm{~S}$ um fato inusitado aconteceu e depois se tornou tema de uma cobertura em massa, em periódicos, nas redes sociais e principalmente, no youtube. Foi, aliás, o youtube que fez a primeira difusão do fato. Após a manifestação, grupos de pessoas ainda permaneciam nas ruas ao redor do congresso. A polícia começou a cargar contra os manifestantes. As imagens que vimos no youtube e que infelizmente, foram retiradas da rede, mostravam um grupo grande de jovens que entra em um bar para não ser abordado por policiais. Estes, os policiais, tentam entrar no bar, porém um senhor de 50 anos de idade, que trabalhava no local, grisalho, bem acima do peso, desesperado os impede. Ele posteriormente, foi chamado de "O Bom Homem do 25S".

Em outro vídeo postado no youtube (www.youtube.com), o "bom homem" fala na frente das câmeras, junto à porta na qual defendeu com seu corpo os manifestantes. Ele diz que os manifestantes são os heróis, não ele, porque ele não teve coragem para ir as ruas na demonstração. Pessoas apertam suas mãos, tiram fotos com ele. Segundo as legendas do vídeo, muitos caíram em lágrimas na homenagem; as imagens mostram uma jovem o abraçando e chorando. Pessoas aplaudem. Ele diz: aqui, o bar, é a casa de todos, não tem que ter colhões para entrar.

Interessante que o "bom homem" vira herói tanto do lado dos indignados, quanto da mídia dominante. O homem mais velho, barrigudo, um fraco, que defende outros mais fracos ainda contra a polícia. Ele um simples homem 
do povo, que não foi para as ruas. O mais importante do fato é que podemos conectá-lo com um conceito, o de "entusiasmo para com a revolução" de Foucault.

O texto que Foucault (1984) trata desse "entusiasmo" ou "predisposição para o bem" é um texto curto centrado nas considerações de Kant sobre seu presente, melhor, sobre o acontecimento mais marcante de sua contemporaneidade, a Revolução Francesa. Esse texto já havia nos chamado a atenção no início da pesquisa, quando fizemos relações entre ele, o desejo de multidão e os indignados. Essas relações tomaram consistência em nossa passagem por Barcelona em 2011. Algo nos chamou a atenção e motivou essas relações, algo que nos forçou a pensar. Esse algo ouvimos em uma assembleia, em uma conversa no primeiro contato com indignados e também em um encontro de um coletivo de Barcelona, o AgoraBCN. Notamos nos discursos uma divisão entre as pessoas que saem as ruas e as supostas pessoas que nada fazem contra a crise, um corte no interior da população espanhola. Ouvimos coisas do tipo: "eles ficam em casa vendo televisão, tomando cerveja, enquanto nós estamos na rua apanhando da polícia". "Caminham feito uma manada bovina nas ruas e nada fazem". Ou falas menos duras, como: "nós [o povo] fomos muito bem educados, precisamos ser indisciplinados [...] mas nós [os indignados] nas ruas praticamos a insubmissão voluntária".

O discurso é compreensível, é duro sair às ruas na busca de um mundo melhor para todos, mundo em que não há centros de poder, transcendência, corte entre dominantes e dominados, enquanto a maioria simplesmente, nada faz, ou melhor, faz o jogo do poder em seu silêncio, apoiando o governo. As palavras de Reich lembradas por Deleuze e Guattari (1972) são convenientes: como entender que as pessoas não lutem por uma vida melhor, por qual motivo desejam a repressão? Porém, precisaríamos de uma percepção fina, para entender como os próprios indignados fazem o jogo do poder, despotencializando as lutas nesse tipo de discurso que pode culminar em um derrotismo, e, mais, como "a tal da manada" pode impulsionar as lutas.

Falávamos com um atuante em um coletivo sobre a função da mídia corporativa no auxílio às lutas, e que no El Pais foi exposta a porcentagem do povo espanhol que simpatizava com os indignados, mais de $80 \%$. Ele me disse que pensava que isso era verdade, mas que esses $80 \%$ não estavam nas ruas e por isso nada significavam. No entanto, será que os discursos de pais, mães, avós, vizinhos, parentes, amigos, de pessoas mais velhas, de todos que 
demonstram sua insatisfação com a democracia representativa e com o capitalismo, ou seja, que desejam mesmo que de forma inconsciente uma realidade menos dura, que talvez seja a real democracia, será que isso não é um dos estopins das lutas na Espanha?

Assim, indignados seriam todos os que vivem sob o domínio do capital, que têm sua produção apropriada, que são obrigados a aceitar o modelo político dominante como se fosse a única possibilidade. Se indignados são todos e não apenas uma parcela dos espanhóis, mas todos os que vivem sob o poder, a multidão, a multidão de indignados, a coisa muda de figura e se torna realmente potente.

Aqui vemos a potência revolucionária possibilitada até por aqueles que são passivos à primeira vista. A potência da manada se atualiza quando se torna multidão; pensamos a potência em termos de desejo, desejo de revolução, de mudança, de uma vida melhor. O desejo pensado como entusiasmo, em Kant, para a revolução, mesmo daqueles que não lutam diretamente.

Foucault faz uma resenha inicial de parte do pensamento de Kant

Se se quer responder à questão "Existe um progresso constante no gênero humano?" é necessário determinar se existe uma causa possível desse progresso, mas, uma vez estabelecida essa possibilidade, é preciso mostrar que essa causa atua efetivamente e, para isto, realçar um certo acontecimento que mostre que a causa atua realmente. [...] Não é suficiente que se siga a trama teleológica que torna possível o progresso, é preciso isolar, no interior da história, um acontecimento que tenha valor de signo. Signo de que? Signo da existência de uma causa, de uma causa permanente, que ao longo de toda a história guiaram os homens pela via do progresso. Causa constante da qual se deve então mostrar que agiu outras vezes, que atua no presente e que atuará posteriormente. (Foucault, 1984, p 6-7)

Esse signo é a revolução. Mas para Kant, o importante da revolução não é o fato de ser um grande acontecimento, com suas inversões de poderes, com as quedas de símbolos, mudanças desejadas e que por isso ela é feita. Para Kant, tudo isso acontece a partir de uma violência tal que acaba sendo indesejada. Não se faria novamente, a revolução, sabendo de seus efeitos.

[...] o que faz sentido e o que vai constituir o signo do progresso é que, em torno da revolução, diz Kant, há "uma simpatia de aspiração que 
beira o entusiasmo". O que é importante na revolução, não é a revolução em si, mas o que se passa na cabeça dos que não a fazem ou, em todo caso, que não são os atores principais; é a relação que eles mantêm com essa revolução da qual eles não são agentes ativos. O entusiasmo para com a revolução é signo, segundo Kant, de uma disposição moral da humanidade [...] (Foucault, 1984, p. 9)

Ou seja, o entusiasmo para com a revolução expressa o desejo de insubmissão, a insubmissão voluntária. O mais importante do texto de Foucault sobre Kant é a possibilidade de ampliar os sujeitos de luta na Espanha. E perguntamos: como perceber o entusiasmo para com a revolução do povo espanhol? Para nós isso fica visível nos relatos das acampadas - as tomadas de praças na Espanha, o primeiro momento das lutas no país - quando pessoas que não estavam acampando traziam suprimentos; quando as pessoas que trabalhavam no comércio do entorno colaboravam. Também fica visível na simpatia do povo espanhol para com os indignados, visto em pesquisas de opinião; como diz Castells:

Así, según la encuesta de Metroscopia publicada por El País, el 66\% de los ciudadanos tienen simpatía por el $15-\mathrm{M}$, el $81 \%$ piensa que los indignados tienen razón y el $84 \%$ que tratan de los problemas que afectan directamente a los ciudadanos. El 51\% piensa que los partidos representan sus propios intereses. El $70 \%$ no se siente representado por ningún partido y el $90 \%$ piensa que tienen que cambiar. Los votantes socialistas simpatizan con el movimiento en un $78 \%$, pero también lo hace el $46 \%$ de los votantes del PP. (Castells, 2011)

Ou seja, o entusiasmo, em um primeiro momento, referente à simpatia com os indignados. Um outro sinal é a saída da passividade a partir de uma ação indignada, a do "bom homem", que agiu revolucionariamente. Pôs seu corpo e estabelecimento em risco. Pelo seu olhar e gestos desesperados sabia que poderia ser agredido pela polícia ou preso; sabia que os seus, os jovens poderiam ser presos, contra o que ele lutava, ele estava predisposto para o bem da revolução. 


\section{Considerações finais}

Como em todos os acontecimentos massivos a rotina se manteve: se fez a preparação nas redes comunicativas e houve o êxito de atualização dessas preparações nas ruas. A multidão tomou o espaço urbano. O pacifismo foi um dos elementos principais, mas mesmo assim a polícia foi extremamente, violenta. O elemento diferencial que percebemos no acontecimento nos possibilitou ampliar o conceito de indignados; este não referido apenas as pessoas que saem para as ruas ou que participam da organização dos coletivos, pois pensamos a população como singularidade de indignação.

\section{Referencial teórico}

Castells, M. (2011). Después de la acampada. La Vanguardia. Disponível em: www.lavanguardia.com. Acesso em: 20 jul. 2013

Deleuze, G. \& Guattari, F. (1972). O anti-Édipo: capitalismo e esquizofrenia 1. Trad. Luiz B. L. Orlandi. ed. 34.

Foucault, M. (1984). O que é iluminismo?. Disponível em: http://pt.scribd.com. acesso em: 15 mai. 2013.

Hardt, M. \& Negri, A. (2005). Multidão. Rio de Janeiro: Record.

Hardt, M. \& Negri, A. (2006). Império. Rio de Janeiro: Record.

Sampedro, V. (s.d.) El 25S ha triunfado. Público.es. Disponível em: http://blogs.publico.es. Acesso em: 20 jul. 2013

\section{Documentos da web}

Bambuser: http://bambuser.com

Comisión de Análisis Sol 15M. Informe sobre el 25S. disponível em: http://madrid.tomalaplaza.net. Acesso em: 15 mai. 2013.

Coordinadora 25S: http://coordinadora25s.wordpress.com

El Pais. Directo disponível em: http://politica.elpais.com acesso em: 15 mai. 2013.

Iniciativa debate. El movimiento 25S "ocupa el Congreso": antecedentes, desarrollo y censura en los media mass españoles. Disponível em: http://iniciativadebate.org. Acesso em: 20 jul. 2013. 
La Haine. Actualización 00.50: Desalojan Neptuno tras una última carga. Disponível em: www.lahaine.org. Acesso em: 15 mai. 2013.

Plataforma en Pie. Serie de comunicados post 25A - Comunicado $\mathrm{N}^{\circ} 3$ (Disolución de la Plataforma ¡En Pie!). Disponível em:

https://plataformaenpie.wordpress.com. Acesso em: 20 jul. 2013

Plataforma em Pie. Documento Base. Disponível em: http://plataformaenpie.wordpress.com. Acesso em: 15 mai. 2013.

Kaos en la Red. (VÍDEOS) Madrid, haciendo historia. Disponível em: www.kaosenlared.net. Acesso em: 20 jul. 2013

Youtube. 26S El Buen Hombre 26 septiembre 2012. Disponível em: www.youtube.com. Acesso em: 15 mai. 2013.

Youtube. 26s infiltrados de la policia "coño que soy compañero". Disponível em: www.youtube.com. Acesso em: 20 jul. 2013.

Youtube. Infiltrados de la policía quedan en evidencia \#25S. Disponível em: www.youtube.com. Acesso em: 20 jul. 2013

Wikipedia. Primavera Árabe. Disponível em: http://es.wikipedia.org. Acesso em: 16 jul. 2013. 